\title{
Relationship between ambulatory blood pressure and follow- up clinic blood pressure in elderly patients with systolic hypertension
}

\author{
Robert H. Fagard ${ }^{a}$, Jan A. Staessen ${ }^{a}$, Lutgarde Thijs ${ }^{a}$, Christopher J. Bulpitt ${ }^{b}$, \\ Denis Clement ${ }^{\mathrm{c}}$, Peter W. de Leeuw ${ }^{\mathrm{d}}$, Matti Jääskivi ${ }^{e}$, Giuseppe Mancia ${ }^{f}$, \\ Eoin O'Brien' ${ }^{\text {, }}$ Paolo Palatini ${ }^{\text {, }}$, Jaakko Tuomilehto ${ }^{\mathrm{e}}$ and John Websteri, for the \\ Systolic Hypertension in Europe Trial Investigators
}

\begin{abstract}
Background Patients with elevated clinic blood pressure and normal ambulatory blood pressure have a better prognosis than patients with sustained ambulatory hypertension, and may not have to be treated with antihypertensive drugs. On the contrary, current guidelines emphasize repeated clinic blood pressure measurements for the initiation of antihypertensive therapy.
\end{abstract}

Objective To examine the relationship between ambulatory blood pressure at baseline and clinic blood pressure after 6 months of follow-up in untreated hypertensive patients, and the relationships of these pressures with the subsequent incidence of cardiovascular events.

Methods Patients who were $\geqslant 60$ years old, with systolic clinic blood pressure of $160-219 \mathrm{mmHg}$ and diastolic pressure $<95 \mathrm{mmHg}$, participated in the Systolic Hypertension in Europe trial. The relationship between ambulatory blood pressure at baseline and clinic blood pressure after 6 months of follow-up was examined in 295 patients enrolled in the Ambulatory Blood Pressure Monitoring substudy and randomized to the placebo arm, and who were still on double-blind treatment and not taking other antihypertensive drugs after 6 months followup.

Results Age averaged $70 \pm 6$ years, $41 \%$ were men, and baseline daytime ambulatory blood pressure was $152 \pm 16 / 84 \pm 10 \mathrm{mmHg}$; clinic blood pressure decreased from $173 \pm 10 / 86 \pm 6 \mathrm{mmHg}$ at baseline to $163 \pm 20 /$ $85 \pm 9 \mathrm{mmHg}$ at month 6 . Systolic daytime ambulatory blood pressure at baseline and systolic clinic blood pressure at month 6 were considered normal if $<140 \mathrm{mmHg}$. Of the 74 patients with normal systolic daytime ambulatory blood pressure at baseline, only seven $(9.5 \%)$ had a normal systolic clinic blood pressure during follow-up. Conversely, of the 24 patients with normal follow-up clinic blood pressure, only seven (29\%) had a normal systolic daytime ambulatory blood pressure at baseline. The incidence of cardiovascular events beyond the 6-month visit was significantly related to baseline ambulatory blood pressure but not to follow-up clinic pressure.

Conclusions Baseline daytime ambulatory blood pressure and follow-up clinic blood pressure do not identify the same patients for antihypertensive treatment. Baseline ambulatory pressure is a better predictor of cardiovascular events than follow-up clinic pressure. J Hypertens 22:8187 (c) 2004 Lippincott Williams \& Wilkins.

Journal of Hypertension 2004, 22:81-87

Keywords: ambulatory blood pressure, cardiovascular events, clinic blood pressure, systolic hypertension

${ }^{a}$ Hypertension and Cardiovascular Rehabilitation Unit, Catholic University of Leuven, Leuven, Belgium, ' Imperial College, Hammersmith Hospital, London, UK, ${ }^{\mathrm{c}}$ Department of Cardiology, University of Gent, Gent, Belgium, ${ }^{\mathrm{d}}$ Department of Internal Medicine, University of Maastricht, Maastricht, The Netherlands,

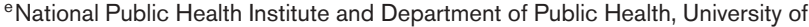
Helsinki, Finland, ${ }^{f}$ Ospedale S. Gerardo, Universitá di Milano, Monza, Italy, ${ }^{g}$ Beaumont Hospital, Dublin, Ireland, h Clinica Medica IV, Universitá di Padova, Padova, Italy and 'Department of Medicine and Therapeutics, University of Aberdeen, Aberdeen, UK

Sponsorship: The Systolic Hypertension in Europe trial was a concerted action of the BIOMED Research program sponsored by the European Union. The trial was carried out in consultation with the World Health Organization, the International Society of Hypertension, the European Society of Hypertension and the World Hypertension League. The trial was sponsored by Bayer AG (Wuppertal, Germany). The National Fund for Scientific Research (Brussels, Belgium) provided additional support. Study medication was donated by Bayer AG and Merck Sharp and Dohme Inc., West Point, Pennsylvania, USA. R.F. is holder of the Prof. A. Amery Chair in Hypertension Research, founded by Merck Sharp \& Dohme.

A list of all Systolic Hypertension in Europe trial participants is available at www.kuleuven.ac.be/hypertension/systeur/index.htm

Correspondence and requests for reprints to R. Fagard, MD, PhD, Professor of Medicine, U.Z. Gasthuisberg - Hypertensie, Herestraat 49, B-3000 Leuven, Belgium.

Tel: +32 163487 07; fax: +32 163437 66;

e-mail: robert.fagard@uz.kuleuven.ac.be

Received 16 June 2003 Revised 22 July 2003

Accepted 18 September 2003

\section{Introduction}

Approximately $25 \%$ of patients with high blood pressure $(\mathrm{BP})$ in the clinic (CBP) have a normal BP on ambulatory blood pressure monitoring (ABP) [1-3]. There is growing evidence that patients with so-called white-coat hypertension (isolated clinic hypertension) 
have a better outcome than patients with sustained hypertension during ABP monitoring, and may not have to be treated with antihypertensive drugs [4-9]. Whereas current guidelines [10-12] consider ABP monitoring for selected patients, the decision to initiate antihypertensive drug treatment is mainly based on repeated CBP measurements, apart from the presence of other risk factors, target organ damage and concomitant clinical conditions such as diabetes and cardiovascular or renal disease. Whereas drug treatment is recommended without much delay in patients at high risk, patients at lower risk should be monitored for several weeks or months, with initiation of drug treatment in cases of persistent CBP elevation in spite of the initiation of lifestyle measures. As far as BP is concerned, guidelines emphasize follow-up CBP, rather than baseline $\mathrm{ABP}$, for the initiation of antihypertensive treatment. The question therefore arises whether patients found hypertensive with high CBP but with normal ABP will develop a normal CBP during followup. Conversely, it is not known whether patients whose CBP normalizes during follow-up are the same as those with white-coat hypertension at baseline. Whereas cross-sectional relationships between $\mathrm{CBP}$ and $\mathrm{ABP}$ have been studied repeatedly [13-15], much less is known on the relationships between baseline ABP and follow-up CBP. Data from the Ambulatory Blood Pressure Monitoring side project of the Systolic Hypertension in Europe (Syst-Eur) trial [16] allow us to address this question. In the Syst-Eur trial [17], 4695 older patients with isolated systolic hypertension were randomized to active treatment or matching placebo and, after termination of the double-blind part of the trial, patients were followed-up on active treatment for another 5 years [18]. ABP was monitored during the single-blind placebo run-in period in 717 participants in the ABP monitoring side project. In the current analysis, we examine the relationships between baseline $\mathrm{ABP}$ and CBP after 6 months of follow-up in patients randomized to the placebo group. In addition, we report on the incidence of cardiovascular events after the 6-month visit in relation to these blood pressures.

\section{Methods}

\section{Trial design}

The protocol of the Syst-Eur trial [17] was approved by the Ethics Committee of the University of Leuven and of the participating centers; all subjects gave informed consent. Eligible patients had to be at least 60 years old. During the run-in period on placebo treatment they were seen at three baseline visits 1 month apart. CBP was measured twice in the sitting position at each visit, using standard sphygmomanometry. Patients could be admitted to the double-blind phase of the trial when they had an average run-in systolic CBP of 160$219 \mathrm{mmHg}$ with diastolic CBP $<95 \mathrm{mmHg}$. After stratification by center, sex and previous cardiovascular complications, the patients were randomized to doubleblind treatment with active medication or matching placebo. Open label medication was allowed for a maximum of 3 months. At each 3-monthly visit the CBP was measured twice in the sitting position and the two pressures were averaged. Biochemical measurements included serum cholesterol $(\mathrm{mmol} / \mathrm{l})$ and serum creatinine $(\mu \mathrm{mol} / \mathrm{l})$. After the end of the double-blind part of the trial [17], the patients of the control group were switched to the active study treatment regimen and followed-up for another 5 years [18].

\section{ABP monitoring}

Of the 198 Syst-Eur centers, 46 agreed to enroll all their patients in the substudy on ABP monitoring, using properly validated and calibrated monitors and appropriate cuff size [16]. All monitors were programmed to record the $\mathrm{BP}$ over an entire 24-h period at intervals no longer than $30 \mathrm{~min}$. At least $80 \%$ of the required recordings had to be available for inclusion in the analysis. Editing criteria encoded in the monitor were disabled or set at limits as wide as possible. No further editing was performed after data acquisition. Means of ambulatory measurements were weighted by the time interval between consecutive readings. Day and night were defined using short fixed clock time periods, ranging from 1000 to $2000 \mathrm{~h}$ and from 000 to $0600 \mathrm{~h}$ [19].

\section{Classification of subgroups}

Patients were classified in subgroups according to the average daytime $\mathrm{ABP}$ at baseline, and according to the CBP at the 6-month visit; only systolic BP was considered in these patients with isolated systolic hypertension. In agreement with current guidelines [10-12] 140 and $160 \mathrm{mmHg}$ were used as cut-off values to define three subgroups for follow-up CBP. According to the recommendations of the Working Group on BP Monitoring of the European Society of Hypertension [20], a daytime ABP $>140 \mathrm{mmHg}$ is abnormal and a pressure $<135 \mathrm{mmHg}$ is considered normal. In our primary analysis we used $140 \mathrm{mmHg}$ as the lower cutoff point for daytime ABP. Some relevant results are also given on the smaller number of patients with daytime ABP $<135 \mathrm{mmHg}$. An ABP level of 160 $\mathrm{mmHg}$ was taken as the higher cut-off point for daytime ABP.

\section{Cardiovascular events during follow-up}

With regard to outcome we considered cardiovascular events, which occurred after the 6-month follow-up visit, including the extended follow-up part of the SystEur trial [18]. Cardiovascular events comprised cardiovascular death, all stroke, all myocardial infarction and all heart failure, as previously described [17]. The analysis on outcome was performed according to the intention-to-treat principle. 


\section{Statistical analysis}

Database management and statistical analysis were performed with SAS software, version 6.12 (SAS Institute Inc., Cary, North Carolina, USA). Data are reported as means \pm standard deviations. Within-group comparisons were performed by paired Student's $t$ test. Comparisons among groups were done by one-way analysis of variance; in case of significance of the overall $P$ value, intergroup comparisons were made by Scheffe's multiple means tests. Relationships between variables were studied by use of single regression analysis. Rates of events were calculated as the number of events divided by the total follow-up time and are expressed as events/1000 patient-years. All tests were two-sided. $P<0.05$ was considered significant.

\section{Results}

\section{Patient population}

ABP monitoring was performed during the single-blind placebo run-in period in a total of 717 patients, of whom 695 had successful measurements. The current analysis was restricted to patients randomized to the placebo group, who were still on double-blind treatment and not taking other antihypertensive drugs after 6 months of follow-up. Among the 353 patients of the placebo group, 310 were still on double-blind treatment after 6 months. Fifteen patients were taking open-label antihypertensive medication, leaving 295 patients for further analysis. Their age averaged 70.0 \pm 6.1 years, the body mass index was $26.8 \pm 3.9 \mathrm{~kg} / \mathrm{m}^{2}$, and $41 \%$ were men. The mean of six CBPs was $173 \pm 10 /$ $86 \pm 6 \mathrm{mmHg}$, daytime ABP was $152 \pm 16 / 84 \pm 10$ $\mathrm{mmHg}$ and night-time ABP $133 \pm 17 / 70 \pm 10 \mathrm{mmHg}$. During the run-in period, CBP averaged $174 \pm 13$ /
$87 \pm 7 \mathrm{mmHg}$ at the first visit, and $174 \pm 14 / 87 \pm 8$ and $171 \pm 13 / 85 \pm 7 \mathrm{mmHg}$, respectively, at the second and third visits. Serum creatinine averaged $89.0 \pm$ $17.4 \mu \mathrm{mol} / \mathrm{l}$ and serum cholesterol $6.02 \pm 1.02 \mathrm{mmol} / \mathrm{l}$. Ten percent of the patients were current smokers, $10 \%$ had diabetes, $2.0 \%$ a history of myocardial infarction and $1.4 \%$ a history of stroke. These characteristics were similar in the 58 patients who were excluded from the analysis.

\section{Follow-up clinic blood pressure}

In the 295 patients, systolic CBP decreased from $172.8 \pm 10.4 \mathrm{mmHg}$ at baseline to $162.8 \pm 19.7 \mathrm{mmHg}$ after 6 months of follow-up $(P<0.001)$, whereas diastolic CBP decreased from $86.2 \pm 5.9$ to $85.0 \pm 9.1 \mathrm{mmHg}$ $(P<0.05)$. A small change in heart rate, from $73.3 \pm$ 9.1 to $72.3 \pm 9.7$ beats $/ \mathrm{min}$, was also observed $(P<$ $0.05)$.

\section{General characteristics according to blood pressure category}

Tables 1 and 2 summarize the general characteristics of the patients at baseline, either according to baseline systolic daytime ABP or according to follow-up systolic CBP. Subgroups did not differ with regard to age, gender, body mass index or heart rate. The ABP and CBP, except diastolic CBP, increased with higher levels of systolic daytime ABP. Patients with higher systolic CBP at follow-up had higher systolic BPs at baseline. Serum cholesterol, serum creatinine, current smoking, and prevalence of diabetes and history of myocardial infarction did not differ between the groups. The subgroup with systolic daytime $\mathrm{ABP} \geqslant 160 \mathrm{mmHg}$ included more patients with a history of stroke than the

Table 1 Baseline characteristics in three subgroups according to systolic daytime ambulatory blood pressure (ABP) at baseline

\begin{tabular}{|c|c|c|c|c|}
\hline & \multicolumn{3}{|c|}{ Systolic daytime ABP at baseline } & \multirow[b]{2}{*}{$P^{a}$} \\
\hline & $<140 \mathrm{mmHg}$ & $140-159 \mathrm{mmHg}$ & $\geqslant 160 \mathrm{mmHg}$ & \\
\hline Number & 74 & 134 & 87 & - \\
\hline Age (years) & $70.3 \pm 5.7$ & $69.7 \pm 6.2$ & $70.1 \pm 6.2$ & 0.78 \\
\hline Gender ( $\%$ men) & 39 & 44 & 39 & 0.70 \\
\hline Body mass index $\left(\mathrm{kg} / \mathrm{m}^{2}\right)$ & $27.2 \pm 3.8$ & $26.4 \pm 4.0$ & $27.1 \pm 3.7$ & 0.22 \\
\hline Heart rate (beats/min) & $71.3 \pm 8.0$ & $74.3 \pm 9.2$ & $73.6 \pm 9.7$ & 0.08 \\
\hline \multicolumn{5}{|c|}{ Systolic blood pressure $(\mathrm{mmHg})$} \\
\hline \multicolumn{5}{|c|}{ Ambulatory } \\
\hline Daytime & $132.6 \pm 5.5$ & $149.6 \pm 5.5$ & $172.2 \pm 9.9$ & - \\
\hline Night-time & $119.1 \pm 11.8$ & $131.5 \pm 13.5^{*}$ & $148.8 \pm 14.4^{*, * *}$ & $<0.001$ \\
\hline Clinic & $168.6 \pm 6.4$ & $171.5 \pm 9.1$ & $178.4 \pm 12.6^{*, * *}$ & $<0.001$ \\
\hline \multicolumn{5}{|l|}{$\begin{array}{l}\text { Diastolic blood pressure } \\
(\mathrm{mmHg})\end{array}$} \\
\hline \multicolumn{5}{|l|}{ Ambulatory } \\
\hline Daytime & $78.1 \pm 7.6$ & $83.6 \pm 8.8^{*}$ & $90.7 \pm 10.5^{*, * *}$ & $<0.001$ \\
\hline Night-time & $66.6 \pm 8.2$ & $69.3 \pm 8.6$ & $75.3 \pm 10.9^{*, * *}$ & $<0.001$ \\
\hline Clinic & $85.6 \pm 5.1$ & $86.2 \pm 6.7$ & $86.9 \pm 5.4$ & 0.39 \\
\hline
\end{tabular}

Values presented as mean \pm standard deviation or percentage of patients. $P$ values are from multiple means tests. ${ }^{\text {a }} P$ values from one-way analysis of variance. ${ }^{*} P \leqslant 0.05$ versus systolic daytime $\mathrm{ABP}<140 \mathrm{mmHg}$. ${ }^{* *} P \leqslant 0.05$ versus systolic daytime ABP of $140-159 \mathrm{mmHg}$. 
Table 2 Baseline characteristics in three subgroups according to systolic clinic blood pressure (CBP) after 6 months of follow-up

\begin{tabular}{|c|c|c|c|c|}
\hline & \multicolumn{3}{|c|}{ Systolic daytime CBP at 6 months } & \multirow[b]{2}{*}{$P^{a}$} \\
\hline & $<140 \mathrm{mmHg}$ & $140-159 \mathrm{mmHg}$ & $\geqslant 160 \mathrm{mmHg}$ & \\
\hline Number & 24 & 116 & 155 & \\
\hline Age (years) & $70.7 \pm 5.5$ & $69.2 \pm 5.6$ & $70.4 \pm 6.5$ & 0.26 \\
\hline Gender (\% men) & 37 & 44 & 40 & 0.75 \\
\hline Body mass index $\left(\mathrm{kg} / \mathrm{m}^{2}\right)$ & $27.5 \pm 5.1$ & $26.3 \pm 3.6$ & $27.1 \pm 3.9$ & 0.22 \\
\hline Heart rate (beats $/ \mathrm{min}$ ) & $73.7 \pm 9.2$ & $72.8 \pm 8.4$ & $73.4 \pm 9.7$ & 0.74 \\
\hline \multicolumn{5}{|c|}{ Systolic blood pressure $(\mathrm{mmHg})$} \\
\hline \multicolumn{5}{|l|}{ Ambulatory } \\
\hline Daytime & $146.5 \pm 14.3$ & $146.5 \pm 15.3$ & $156.9 \pm 15.9^{*, * *}$ & $<0.001$ \\
\hline Night-time & $128.3 \pm 15.3$ & $128.3 \pm 16.1$ & $138.2 \pm 17.3^{*, * *}$ & $<0.001$ \\
\hline Clinic & $169.8 \pm 10.8$ & $167.9 \pm 6.1$ & $176.9 \pm 11.2^{*, * *}$ & $<0.001$ \\
\hline \multicolumn{5}{|l|}{$\begin{array}{l}\text { Diastolic blood pressure } \\
(\mathrm{mmHg})\end{array}$} \\
\hline \multicolumn{5}{|l|}{ Ambulatory } \\
\hline Daytime & $84.1 \pm 9.7$ & $83.6 \pm 11.3$ & $84.8 \pm 9.3$ & 0.60 \\
\hline Night-time & $68.8 \pm 11.5$ & $70.1 \pm 9.5$ & $70.9 \pm 9.8$ & 0.57 \\
\hline Clinic & $85.1 \pm 5.0$ & $86.1 \pm 5.6$ & $86.5 \pm 6.3$ & 0.53 \\
\hline
\end{tabular}

Values presented as mean \pm standard deviation or percentage of patients. $P$ values are from multiple means tests. ${ }^{\text {a }} P$ values from one-way analysis of variance. ${ }^{*} P \leqslant 0.05$ versus systolic daytime ABP $<140 \mathrm{mmHg}$. ${ }^{* *} P \leqslant 0.05$ versus systolic daytime ABP of $140-159 \mathrm{mmHg}$.

other groups (4.6 versus $0 \% ; P<0.01)$, but stroke prevalence did not differ according to follow-up CBP.

\section{Relationships between ambulatory and clinic blood pressure}

Figure 1 illustrates the relationships between systolic daytime $\mathrm{ABP}$ at baseline, and, respectively, systolic $\mathrm{CBP}$ at baseline and systolic CBP after 6 months of follow-up. Both CBPs were significantly related to ABP at baseline. The relationship was significantly steeper for follow-up CBP than for baseline CBP $(P=0.002)$. The regression equations were similar in men and women. Baseline systolic daytime $\operatorname{ABP}(X)$ was a significant predictor of the change in systolic CBP from baseline to month $6(Y): Y=-36.8+0.18 \times X \quad(r=$ $+0.18 ; P=0.002)$; CBP decreased more when baseline $\mathrm{ABP}$ was low.

Table 3 summarizes the number of patients in each of nine subcategories according to the three categories based on systolic daytime $\mathrm{ABP}$ at baseline and the three categories based on systolic CBP at month 6. Of the 74 patients with baseline systolic daytime $\mathrm{ABP}<140 \mathrm{mmHg}$, only seven $(9.5 \%)$ had a normal systolic CBP $(<140 \mathrm{mmHg})$ during follow-up, whereas systolic CBP remained $\geqslant 160 \mathrm{mmHg}$ in $22(30 \%)$ patients. Among 87 patients with systolic daytime $\mathrm{ABP} \geqslant 160 \mathrm{mmHg}$ at baseline, $62(71 \%)$ also had a systolic $\mathrm{CBP} \geqslant 160 \mathrm{mmHg}$ at month 6 . Systolic CBP normalized in 24 patients during follow-up, of whom seven (29\%) had a systolic daytime ABP at baseline of $<140 \mathrm{mmHg}$.

Systolic daytime ABP at baseline was $<135 \mathrm{mmHg}$ in 45 patients. CBP at month 6 was $<140 \mathrm{mmHg}$ in four
Fig. 1

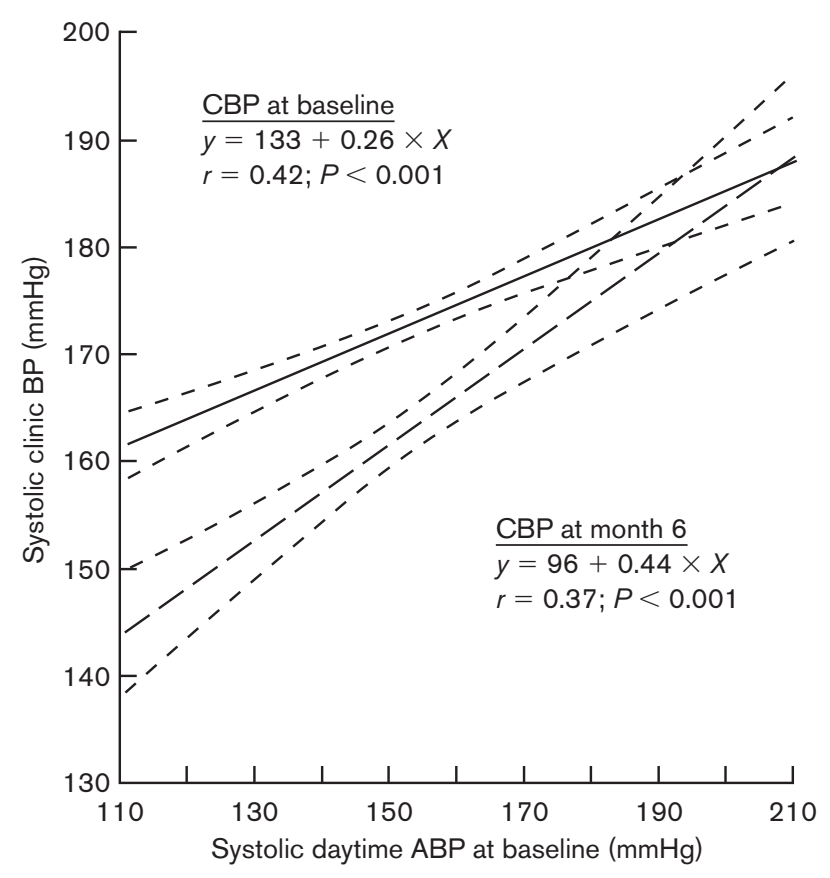

Relationship of systolic daytime ambulatory blood pressure $(A B P)$ at baseline with, respectively, systolic clinic blood pressure (CBP) at baseline, and systolic CBP after 6 months of follow-up. The figure shows the regression lines and the $95 \%$ confidence limits. The slopes are significantly different $(P=0.002)$.

of these patients $(8.9 \%)$, between 140 and $159 \mathrm{mmHg}$ in $30(67 \%)$ patients and $\geqslant 160 \mathrm{mmHg}$ in $11(24 \%)$ patients. Among the 24 patients with normal systolic CBP after 6 months, baseline daytime systolic ABP was $<135 \mathrm{mmHg}$ in only four patients (17\%). 
Table 3 Distribution of patients according to systolic daytime ambulatory blood pressure (ABP) at baseline and systolic clinic blood pressure (CBP) after 6 months of follow-up

\begin{tabular}{|c|c|c|c|c|}
\hline \multirow[b]{2}{*}{ Systolic CBP at month 6} & \multicolumn{4}{|c|}{ Systolic daytime ABP at baseline } \\
\hline & $<140 \mathrm{mmHg}$ & $140-159 \mathrm{mmHg}$ & $\geqslant 160 \mathrm{mmHg}$ & All \\
\hline$<140 \mathrm{mmHg}$ & 7 & 12 & 5 & 24 \\
\hline $140-159 \mathrm{mmHg}$ & 45 & 51 & 20 & 116 \\
\hline$\geqslant 160 \mathrm{mmHg}$ & 22 & 71 & 62 & 155 \\
\hline All & 74 & 134 & 87 & 295 \\
\hline
\end{tabular}

Data presented as numbers of patients.

\section{Cardiovascular events}

The median follow-up time after the 6-month visit was 7.5 years, ranging from 0.5 to 13 years. During this period, 58 of the 295 patients suffered a cardiovascular event, which corresponds to a rate of 28.1 events per 1000 patient years. Table 4 presents the results in the nine subgroups. In the three groups according to systolic daytime $\mathrm{ABP}$, the event rate increased with increasing levels of ABP; the event rate was significantly $(P=0.02)$ higher in patients with $\mathrm{ABP} \geqslant 160$ $\mathrm{mmHg}(40.5)$ than in patients with $\mathrm{ABP}<140 \mathrm{mmHg}$ (18.9). There were no significant differences among the three groups based on follow-up CBP. It is unlikely that these results have been confounded by other risk factors such as age, gender, relative weight, serum cholesterol, smoking, diabetes and heart rate because they did not differ among the subgroups. Finally, six of the 45 patients with daytime systolic $\mathrm{ABP}<135$ $\mathrm{mmHg}$ suffered a cardiovascular event (event rate, 19.3 events per 1000 patient-years).

\section{Discussion}

The major findings of the present study in older patients with systolic hypertension randomized to the placebo arm of the Syst-Eur trial are: (1) that there is a poor relationship between $\mathrm{ABP}$ at baseline and followup CBP, (2) that patients with normal ABP at baseline do not necessarily develop a normal CBP during followup, and (3) that patients with normal CBP during follow-up did not necessarily have a normal ABP at baseline. In addition, baseline $\mathrm{ABP}$ predicted the incidence of cardiovascular events, which was not the case for follow-up CBP.

These findings have consequences for patient management. It has indeed been shown that white-coat hypertension is associated with a better prognosis than sustained ambulatory hypertension [4-9]. Verdecchia et al. [4] even observed that cardiovascular outcome was similar in patients with white-coat hypertension and in true normotensive subjects with normal CBP and normal ABP. The better outcome in white-coat hypertension than in sustained hypertension was also observed in the double-blind part of the Syst-Eur trial [7]. The incidence of stroke was 7.3 per 1000 patient-years in patients with systolic daytime $\mathrm{ABP}<140 \mathrm{mmHg}$ and this figure amounted to 27.8 when this pressure was $\geqslant 160 \mathrm{mmHg} \quad(P=0.03)$. The rates of cardiovascular events were, respectively, 22.1 and 59.5 events per 1000 patient-years $(P=0.01)$. In addition, antihypertensive drug treatment did not significantly affect the incidence of stroke and of cardiovascular complications when the systolic daytime ABP was low. These findings suggest that patients with white-coat hypertension may not have to be treated with antihypertensive drugs, but that careful monitoring and appropriate non-pharmacological measures may suffice. However, if one accepts that patients whose CBP does not normalize after 6 months of follow-up require antihypertensive treatment, drugs should be instituted in $90 \%$ of these patients, despite the normal ABP at baseline. Systolic CBP was normal in only 24 of the 295 patients after

Table 4 Incidence of cardiovascular events, beyond the 6-month visit, according to systolic daytime ambulatory blood pressure (ABP) at baseline and systolic clinic blood pressure (CBP) after 6 months of follow-up

\begin{tabular}{lccrr}
\hline & \multicolumn{4}{c}{ Systolic daytime ABP at baseline } \\
\cline { 2 - 5 } Systolic CBP at month 6 & $<140 \mathrm{mmHg}$ & $140-159 \mathrm{mmHg}$ & $\geqslant 160 \mathrm{mmHg}$ & All \\
\hline$<140 \mathrm{mmHg}$ & $2 / 7(-)$ & $2 / 12(-)$ & $2 / 5(-)$ & $6 / 24(34.7)$ \\
$140-159 \mathrm{mmHg}$ & $5 / 45(16.2)$ & $8 / 51(24.9)$ & $6 / 20(45.9)$ & $19 / 116(25.0)$ \\
$\geqslant 160 \mathrm{mmHg}$ & $3 / 22(-)$ & $13 / 71(25.4)$ & $17 / 62(37.5)$ & $33 / 155(29.1)$ \\
All & $10 / 74(18.9)$ & $23 / 134(24.9)$ & $25 / 87(40.5)^{*}$ & $58 / 295(28.1)$ \\
\hline
\end{tabular}

Data presented as number of events/number of patients (rate of events per 1000 patient-years). Rates in subgroups are only given when $\geqslant 5$ cardiovascular events occurred. ${ }^{*} P=0.02$ versus $A B P<140 \mathrm{mmHg}$. 
6 months of follow-up. However, baseline systolic daytime ABP was $\geqslant 140 \mathrm{mmHg}$ in $71 \%$ of these patients $(\geqslant 135 \mathrm{mmHg}$ in $83 \%)$, so that drug treatment would have been indicated according to ABP after the baseline observations, but not according to follow-up CBP.

It is difficult to compare our results with those from previous studies because of different study populations and study design. Nevertheless, our results are in keeping with the general conclusion that baseline ABP and follow-up CBP do not identify the same patients for the initiation of antihypertensive treatment or as having sustained hypertension. Chatellier et al. [21] studied the predictive value of one baseline daytime ABP monitoring for the initiation of antihypertensive treatment according to the 1989 World Health Organization/International Society of Hypertension guidelines for the management of mild hypertension. Patients with diastolic CBP of $90-104 \mathrm{mmHg}$ at the second clinic visit were followed up over 6 months. The authors concluded that the predictive value of ABP, that is a diastolic ABP of two standard deviations above age-specific values in normotensive volunteers, was too low to detect with confidence those patients who need treatment according to the 1989 World Health Orgnization/International Society of Hypertension guidelines. Stergiou et al. [22] investigated whether BP measurement by $\mathrm{ABP}$ monitoring is a reliable alternative to the traditional strategy for the diagnosis of hypertension based on BP measurement on repeated clinic visits over 3 months. They enrolled patients with a diastolic CBP of $90-115 \mathrm{mmHg}$ and systolic $\mathrm{CBP}<180 \mathrm{mmHg}$ on the initial visit. The same BP threshold of at least $140 \mathrm{mmHg}$ systolic, of at least $90 \mathrm{mmHg}$ diastolic, or both, was used for the diagnosis of hypertension using each method, i.e. at the last clinic visit, or the average awake ABP of two recordings. Disagreement between CBP and ABP was observed in $27 \%$ of the patients. Finally, Palatini [23] observed that ABP was not a good predictor of the systolic CBP fall during the following 6 months of observation in 66 elderly subjects with mild hypertension.

The question arises whether the decision to initiate antihypertensive therapy should be based on baseline ABP or on follow-up CBP. Our data on outcome could favor the baseline ABP because ABP significantly predicted subsequent cardiovascular events, whereas CBP after 6 months of follow-up did not.

The present study confirms the substantial difference between systolic CBP and systolic daytime ABP at baseline in older patients with systolic hypertension [15]. In addition, CBP decreased further during followup on placebo, despite the fact that in these patients baseline CBP was the mean of three duplicate measurements over a 3 -month period. The drop in GBP appeared to be most pronounced in patients with low systolic daytime ABP at baseline.

A number of limitations have to be considered with regard to the present findings. The analysis was performed in older patients with systolic hypertension defined as systolic $\mathrm{CBP} \geqslant 160 \mathrm{mmHg}$ and diastolic CBP $<95$ mmHg. Furthermore, the baseline CBP was the average of two CBPs at each of three visits 1 month apart. Results are likely to differ in other patient populations and with less frequent or standardized CBP measurements. Nevertheless, Chatellier et al. [21] and Stergiou et al. [22] reached similar conclusions from differently designed studies. Whereas the definitions of hypertension and of grades of severity of hypertension are well established [10-12], there is as yet no definitive definition of white-coat hypertension, and particularly isolated systolic white-coat hypertension. We used $140 \mathrm{mmHg}$ as the cut-off point for systolic daytime $\mathrm{ABP}$ in our primary analysis, but also presented data for the lower level of $135 \mathrm{mmHg}$ [20]. We have based our analysis on the CBP after 6 months of follow-up. It could be argued that the CBP would normalize in more patients after a longer follow-up period. However, the average CBP remained stable beyond 6 months in the placebo group of the Syst-Eur trial [17]. The classification of patients in subgroups according to ABP might have been different if more than one 24-h recording was taken due to regression-to-the-mean [24]. In addition, ABP monitoring was not systematically performed at month 6. However, recordings after 1 year showed that the average ABP differed only slightly from the baseline values [25]. With regard to outcome, the present analysis is based on a small subgroup of patients from the Syst-Eur trial, so the number of events is relatively small. Larger studies are therefore warranted to assess the relationship between, respectively, baseline ABP and follow-up CBP, and the incidence of cardiovascular events.

In conclusion, the selection of older patients with isolated systolic hypertension for antihypertensive treatment differs according to whether the decision is based on baseline ABP or on follow-up CBP. Data on outcome may favor baseline ABP.

\section{Acknowledgement}

The authors gratefully acknowledge the secretarial assistance of N. Ausseloos.

\section{References}

1 Staessen J, O'Brien ET, Atkins N, Amery AK, on behalf of the Ad-Hoc Working Group. Short report: ambulatory blood pressure in normotensive compared with hypertensive subjects. J Hypertens 1993; 11: 1289-1297.

2 Mancia G, Zanchetti A. White-coat hypertension: misnomers, misconceptions and misunderstandings. What should we do next? J Hypertens 1996; 14:1049-1052. 
3 Pickering TG. White coat hypertension. Curr Opin Nephrol Hypertens 1996; 5:192-198.

4 Verdecchia P, Porcellati C, Schillaci G, Borgioni C, Ciucci A, Battistelli $\mathrm{M}$, et al. Ambulatory blood pressure: an independent predictor of prognosis in essential hypertension. Hypertension 1994; 24:793-801.

5 Khattar RS, Senior R, Lahiri A. Cardiovascular outcome in white-coat versus sustained mild hypertension: a 10-year follow-up study. Circulation 1998; 98:1892-1897.

6 Redon J, Campos C, Narciso ML, Rodicio JL, Pascual JM, Ruilope LM. Prognostic value of ambulatory blood pressure monitoring in refractory hypertension: a prospective study. Hypertension 1998; 31:712-718.

7 Fagard RH, Staessen JA, Thijs L, Gasowski J, Bulpitt CJ, Clement D, et al. Response to antihypertensive therapy in patients with sustained and nonsustained systolic hypertension. Circulation 2000; 102:1139-1144.

8 Kario K, Shimada K, Schwartz JE, Matsuo T, Hoshide S, Pickering TG. Silent and clinically overt stroke in older Japanese subjects with whitecoat and sustained hypertension. J Am Coll Cardiol 2001; 38:238-245.

9 Celis H, Staessen JA, Thijs L, Buntinx F, De Buyzere M, Den Hond E, et al. Cardiovascular risk in white-coat and sustained hypertensive patients. Blood Press 2002; 11:352-356.

10 Chobanian AV, Bahris GL, Black HR, Cushman WC, Green LA, Izzo JL, et al. The Seventh Report of the Joint National Committee on Prevention, Detection, Evaluation and Treatment of High Blood Pressure. JAMA 2003; 289:2560-2572.

11 Guidelines Subcommittee. 1999 World Health Organization-International Society of Hypertension Guidelines for the Management of Hypertension. J Hypertens 1999; 17:151-183.

12 Guidelines Committee. 2003 European Society of Hypertension-European Society of Cardiology Guidelines for the Management of Arterial Hypertension. J Hypertens 2003; 21:1011-1053.

13 Mancia G, Sega R, Bravi C, De Vito G, Valagussa F, Cesana G, et al. Ambulatory blood pressure normality: results from the PAMELA study. J Hypertens 1995; 13:1377-1390.

14 Staessen JA, Bieniaszewski L, O'Brien ET, Imai Y, Fagard R. An epidemiological approach to ambulatory blood pressure monitoring: the Belgian Population Study. Blood Press Monit 1996; 1:13-26.

15 Thijs L, Celis H, Clement D, Gil-Extremera B, Kawecka-Jaszcz K, Mancia $\mathrm{G}$, et al. Conventional and ambulatory blood pressure measurement in older patients with isolated systolic hypertension: second progress report on the ambulatory blood pressure monitoring project in the Syst-Eur trial. Blood Press Monit 1996; 1:95-103.

16 Staessen J, Amery A, Clement D, Cox J, Fagard R, Guo C, et al. Twentyfour hour blood pressure monitoring in the Syst-Eur Trial. Aging Clin Exp Res 1992; 4:85-91.

17 Staessen JA, Fagard R, Thijs L, Celis H, Arabidze GG, Birkenhäger WH, et al. Randomized double-blind comparison of placebo and active treatment for older patients with isolated systolic hypertension. Lancet 1997; 350:757-764.

18 Gasowski J, Staessen JA, Celis H, Fagard RH, Thijs L, Birkenhäger WH, et al. Systolic Hypertension in Europe (Syst-Eur) Trial Phase 2: objectives, protocol and initial progress. J Hum Hypertens 1999; 13: $135-145$

19 Fagard R, Brguljan J, Thijs L, Staessen J. Prediction of the actual awake and asleep blood pressures by various methods of 24-h pressure analysis. J Hypertens 1996; 14:557-563.

20 O'Brien E, Asmar R, Beilin L, Imai Y, Mallion J-M, Mancia G, et al. European Society of Hypertension recommendations for conventional, ambulatory and home blood pressure measurements. Blood Press Monit 2003; $21: 821-848$.

21 Chatellier G, Battaglia C, Pagny J-Y, Plouin P-F, Ménard J. Decision to treat mild hypertension after assessment by ambulatory monitoring and World Health Organisation recommendations. BMJ 1992; 305: 1062-1066.

22 Stergiou GS, Skeva II, Baibas NM, Kalkana CB, Roussias LG, Mountokalakis TD. Diagnosis of hypertension using home and ambulatory blood pressure monitoring: comparison with the conventional strategy based on repeated clinic blood pressure measurements. J Hypertens 2000; 18:1745-1751.

23 Palatini P. Too much of a good thing? A critique of overemphasis on the use of ambulatory blood pressure monitoring in clinical practice. J Hypertens 2002; 20:1917-1923.

24 Palatini P, Dorigatti F, Roman E, Giovinazzo P, Piccolo D, De Venuto G, et al. White coat hypertension: a selection bias? J Hypertens 1998; 16:977-984.

25 Staessen JA, Thijs L, Clement D, Davidson C, Fagard R, Lehtonen A, et al. Ambulatory pressure decreases on long-term placebo treatment in older patients with isolated systolic hypertension. J Hypertens 1994; 12:1035-1039. 